\title{
Exploratory Thinking on the Construction of Independent College Foreign Language Education
}

\author{
Baohong Li \\ Department of Basic Education, College of Optical and Electronical Information, Changchun \\ University of Science and Technology, Changchun, 130000, China.
}

Email: 4566254@qq.com

\begin{abstract}
Keywords: Independent Colleges; Foreign Language Education; Evaluation System
\end{abstract}
\begin{abstract}
The State Council Executive Meeting was held in early 2014. To accelerate the development of Modern Vocational Education, and "lead a group of local undergraduate colleges and universities to transform into the applied and technical colleges and universities" was explicitly proposed. It means that parts of the local colleges and universities transform into the applied and technical colleges and universities, which has become a national strategic decision. In this context, increasing foreign language education evaluation system research is helpful to promote the independent colleges to walk the road of transformation and development. One of the most important evaluation methods of the formative assessment is the principle of diversification. This evaluation method should break the previous summative way to take including teachers' evaluation, students' self-evaluation, students' mutual evaluation, observation, questionnaires, activity records, interviews and other diversified methods. An investigation research on foreign language education method of independent college in Jilin Province from the diversified evaluation principle of formative evaluation will be carried out. Exploratory thinking on the construction of independent college foreign language education will be put forward guided by the constructivism theory of diversified teaching evaluation and combined with the reform experiments of diversified teaching evaluation implemented in our college. So it can promote the reform of college English evaluation system smoothly.
\end{abstract}

\section{Current Situation of Independent College Foreign Language Education Evaluation System}

At present, Independent College Education Evaluation is mostly reflected in the college English teaching evaluation. In order to complete the investigation of college English current situation, the author has done a lot of surveys and interviews among college English teachers and students of non-English majors from eight independent colleges within the scope of Jilin Province. 160 questionnaires are distributed in the survey, 145 is withdrawn. The effective rate was $91 \%$. The main contents of the questionnaire include the following aspects: the major evaluation methods of current college English; the evaluation subject of usual-time mark, its evaluation foundation and its proportion of the overall grade; the structure and its validity of final exam, the opening situation of speaking and listening course and its proportion in evaluation; the relationship between the current evaluation system and the students' English learning; the evaluation method really reflecting the students' foreign language level, etc.

In the survey, most of the independent colleges usually take the pattern of "usual-time mark + exam mark" based on the summative evaluation method. The proportion of usual-time mark in the overall mark is $20 \%, 30 \%, 40 \%$ and $50 \%$ respectively. The number of respondents who considers usual-time mark accounting for $20 \%$ in the overall mark is about $20 \%$, accounting for $30 \%$ of the number of respondents is about $52 \%$, accounting for $40 \%$ of the number of respondents is about $21 \%$, accounting for $50 \%$ of the number of respondents is about $7 \%$.The proportion of usual-time mark in overall mark in most Independent Colleges is not high. The majority concentrates in the proportion of $30 \%$. The main subjects of usual-time evaluation consist of teachers' evaluation, students' self-evaluation, others' evaluation, diversified evaluation. Moreover, teacher's evaluation accounts for $85 \%$, students' self-evaluation accounts for $4 \%$, others' evaluation accounts for $5 \%$, 
diversified evaluation accounts for $6 \%$. So it can be seen that teacher evaluation has a dominant position in the usual-time mark evaluation. On the contents of usual-time evaluation, the students' classroom performance, homework and attendance take up a dominant position. Listening, speaking, quizzes and others take up a very small proportion. In addition, it is important to note that most of the teachers and students think that the structure of final exam paper is the same or similar as the structure of CET4 or CET6. The final exam has been basically CET4 or CET6 patterned.

\section{The Theoretical Foundation of Independent College Foreign Language Education Evaluation System}

Constructivism emerged in the 1880s, also known as structuralism, is a new kind of cognitive theory. The first researcher of Constructivism is Jean Piaget. Then Kohlberg, Sternberg, Katz, Bruner improved and developed it, so it got a wide range of applications in teaching [1]. Constructivism emphasizes diversified evaluation methods in teaching evaluation [2]. On the subject of evaluation, Constructivism emphasizes the diversification of evaluation subject, namely students' personal evaluation, evaluation of others, group evaluation and teacher evaluation should be organically combined to form group evaluation subjects. On evaluation methods, constructivism not only stresses the importance of quantity and quality evaluation, but also stresses the unity of the evaluation results and the evaluation processes. In the evaluation method, Constructivism stresses the need to break summative evaluation-traditional test relied on pen and paper, to establish diversified evaluation methods like students' journal, observation and discussion groups, recording, portfolio evaluation, etc. [3]. In addition, Constructivism emphasizes the evaluation process, the evaluation of subject and object should be based on democratic participation and equal consultation, to share the formed results together [4].

Jiagan Dai, vice president of China Education Association has noted that the focus of current exam reform and education reform is to build a scientific education evaluation system. It makes the education evaluation from single test to diversified evaluation. Therefore, the construction of diversified college English evaluation system is conducive to change the traditional evaluation model given priority to summative evaluation, to promote the conduction of college English reform smoothly, to deepen the development of the overall education reform [5].

\section{The Reform Experiment of Independent College Foreign Language Education Evaluation System}

The object of the reform experiment is our college undergraduate in non-English major. A total of 12 natural classes (four class A, eight class B), 425 students are from Grade one and Grade two. The specific content of the experiment is that the students are divided into A, B-two levels, namely Class A and Class B by means of comprehensive examination in their early enrollment. Class A is for the senior class, Class B is for the regular class. It's different between Class A and Class B on the evaluation content and evaluation standards. Class A is slightly higher than Class B. (It mainly reflects on the evaluation of usual-time mark). Usual-time mark rises to $40 \%$ from $20 \%$. The usual-time mark evaluation includes teachers' evaluation, oral evaluation, students' self-evaluation, mutual evaluation and group evaluation. Among them, oral evaluation accounts for $20 \%$ of the usual-time mark. School designates spoken textbooks and the students have one English lesson per week. Oral evaluation are mainly carried out at the end of the semester, supervised and completed by two teachers. Oral evaluation content is to read materials, make a conversation in group of 3 to 5 students and answer the question and so on. Class A is slightly higher than Class B on the evaluation standard. Teacher's evaluation accounts for $10 \%$. Teacher's evaluation mainly depends on the students' comprehensive performance, attendance, quizzes, assignments, etc. To use marks to evaluate students' learning process. Students' self-evaluation and mutual evaluation are mainly undertaken on speaking, listening and other skills training courses. Teachers and students negotiate a set of appropriate evaluation standards before class. Students should make a self performance evaluation or mutual evaluation and write evaluation reports after a phase of skills training (e.g. a 
month). The students' self-evaluation and mutual evaluation will not only stimulate students' interest in learning and creativity, but also to provide information about students' learning ability in English. Other valuable information for teachers can stimulate students' interest in English [6]. Group evaluation accounts for 5\%. The students are divided into several groups according to the principle of 5-8 persons per group. Each group elects a person to form an evaluation team, who makes the evaluation based on the performance and contribution of the group members. Group evaluation will encourage students to participate in group activities and develop their team spirit.

The reform experiment compared with traditional evaluation method has made great progress. First of all, students' learning enthusiasm has been greatly improved. Students English class attendance, class atmosphere, interaction between teachers and students, group discussion, etc. has been improved significantly. Learning attitude transforms from "make me learn" into "I want to learn". More over, the number of the students with such attitude is increasing. The enthusiasm of students is aroused at the same time, participating in the evaluation actively. Second, the application ability of students is significantly enhanced. After this reform experiment, the number of the students who enroll in English competition (such as writing contest, oral test, speech contests, etc.) increase significantly. Various qualities of the competitions and award-winning rate of the students have also been greatly improved. Before the reform experiment, more than $60 \%$ of the students hold the motivation like "not to fail in the exam", "to pass CET4 or CET6", "to get the scholarship". After the reform experiment, the number has dropped to 47\%. However, everything has two sides. Diversified evaluation as good as traditional evaluation system also has some limitations. For example, the evaluation content is not comprehensive, the evaluation process consumes much time, the evaluation standard is difficult to unify.

\section{Exploratory Thinking on the Construction of Independent College Foreign Language Education}

In view of the above analysis and reform experiment, the establishment of the independent college foreign language education evaluation system should follow the following principles. In the first place, Diversified evaluation is carried out which includes formative evaluation, summative evaluation and diagnostic evaluation[7]. Specifically, as the followings, diagnostic evaluation should be done first for the students. That is to say, to make an evaluation about the students' current level of development in all aspects of foreign language. Then, formative evaluation should be done to evaluate students' every aspect of learning process at any time. Such as the ability of all aspects of foreign language includes listening, speaking, reading, writing, translation, learning methods and learning attitudes. Finally, a summative evaluation should be made to evaluate the development of the students' all aspects. In the second place, the evaluation subject should be diversified. Teachers as the main evaluation subjects should be broken in the evaluation process. Students' self-evaluation, mutual evaluation, group evaluation, all kinds of foreign language competition evaluations (such as English speech contest, writing competition, college students' English competition, etc.), all kinds of foreign language evaluation activities, teaching related management personnel evaluation and so on. Only the introduction of diversified evaluation subjects can reflect the students' learning situation truly and effectively and improve the teaching quality. In the third place, evaluation content should be practical and professional. Foreign language education evaluation in Colleges and Universities in Jilin Province mainly adopts the summative evaluation. The evaluation content mostly relies on CET4 or CET6 questions, which is not beneficial to the transformation of the independent college. Speaking, listening, communication, translation and other practical evaluation methods should be increased in foreign language education evaluation system to enable the students to learn more practically. In addition, each independent college can open professional foreign language according to the actual situation and make it become evaluation content. Foreign language education ideas should be reformed to improve the level of foreign language education fundamentally [8]. In the fourth place, the evaluation standards should be diversified. The so-called diversified evaluation standards, from a macro perspective, each independent college can be different from each other according to their 
own teaching conditions and educational goals. From a micro perspective, the teacher can establish their respective development objectives and evaluation standards according to the characteristics of each student [9].

In a word, all aspects of the above mentioned needs students, faculty and the college administration to attach great importance. Colleges and universities should support it from the policy, material and financial resources and assist some effective methods and means to enable the evaluation results and function truly and effectively. So it can reform and improve the evaluation system of Independent College Foreign Language Education to promote sustainable development of university foreign language education. In addition, the author hopes that this article has a certain reference value for the construction of the national college foreign language education evaluation system.

\section{Acknowledgement}

Fund Project: Jilin Province Higher Education Institute of Higher Education Scientific Research Project 2015 " The Research on Foreign Language Education Evaluation System Construction of Independent College in Jilin Province under the Background of Transformation " (Project Number: JGJX2015C111) achievements.

\section{References}

[1] Yansong Feng, Baiwen Li. The diversified evaluation system of college English teaching from the perspective of constructivism theory [J]. Journal of Shandong Institute of Education, 2010 (4): 86.

[2] Yue Chen. Constructivism and constructivism learning theory review [J]. Hui Cun Education, 2002.

[3] Wen Gao. Constructivism learning evaluation [J]. Journal of Foreign Education Information, 1998 (2): 25.

[4] Gaowang Meng, Linlin Yang. Multiple evaluation system of college English under the guidance of constructivism study [J]. Journal of College of Suzhou, 2009 (2): 143.

[5] Jiagan Dai. Transforming our exams [M]. Beijing: Higher Education Press, 2008:1.

[6] Harri, Michael and Paul McCann. Assessment[M].Oxford: Macmillan Heinemann English Language Teaching, 1994.

[7] Qian Guo. Using the formative assessment to promote the cultivation of learners' autonomy in college English teaching [J]. Journal of Xi 'an Foreign Languages Institute, 2004, (6).

[8] Moore, K.D. Effective Instructional Strategies: from Theory to Practice[M].California: Sage Publications, Inc, 2005: 163-165.

[9] Scriven, M. The Methodology of Evaluation[C]//R.W.Tyler,R. Gagne.M.Scriven. Perspectives on Curriculum Evaluation. Chicago: Rand McNally, 1967: 39-83.

Author Introduction: Bao hong Li (1983 -), female, Jilin Province, Nationality Han, Master Degree, College of Optical and Electronical Information, Changchun University of Science and Technology. Research direction: Applied Linguistics. 